\title{
Experimentações em um CAPS Infantil: embalos, criações, intensidades
}

Experimentations in a CAPS Infantil: packs, creations, intensities

Experimentaciones en un CAPS Infantil: movimientos, creaciones, intensidades

\author{
Francine Delavald Bottoni* \\ Luciane Marques Raupp ${ }^{* *}$
}

\begin{abstract}
Resumo
Este escrito se propõe a apresentar uma experiência de estágio em um serviço público de saúde mental, tendo como foco as vivências, dificuldades e inquietações surgidas no percurso de aplicação de uma intervenção, ocorrida em cinco encontros e que visava a trabalhar a equipe de um CAPS Infantil do interior do Rio Grande do Sul, por meio do uso de dispositivos que serviram de disparadores às discussões efetuadas durante as reuniões de equipe do serviço. Autores ligados ao movimento institucionalista foram utilizados, pois a intervenção visava a desnaturalizar e a problematizar o cotidiano de trabalho da equipe, disparando movimentos de inquietação e reflexão nos profissionais. Conclui-se que a vivência dos dispositivos suscitou momentos de criação, de repensar a prática no serviço, problematizar a rotina e o desejo de inventar novos modos de se fazer saúde mental, conduzindo à flexibilização das práticas da equipe local.
\end{abstract}

Palavras-chave: Estágio em saúde mental. CAPS Infantil. Análise institucional.

\begin{abstract}
This writing is intended to present an experience of internship at a public mental health service institution, focusing on the experiences, difficulties, and concerns arising in the course of implementation of an intervention, which occurred in five meetings, aimed at staff working in a CAPS for Children in the interior of Rio Grande do Sul, by use of the following devices, which were used as triggers for discussions during staff meetings in service. Authors linked to the institutional movement were used, because the intervention aimed to deconstruct and problematize the daily work of the team, making movements and reflections on care
\end{abstract}

\footnotetext{
Acadêmica de Psicologia do Centro Universitário Univates. Endereço: Rua Piauí, no 519 - Bairro São Cristóvão, LajeadoRS. CEP: 95900-000. E-mail: fbottoni@universo.univates.br.

** Doutora em Saúde Pública (USP), docente do Curso de Psicologia do Centro Universitário Univates.
} 
professionals. The experience of devices provided moments of creation, to rethink practices used in service, discuss the routines and the desire to invent new ways to work with mental health, leading flexibility and to easing the practices for the local team.

Keywords: Internship in mental health. CAPS Infantil. Institutional analysis.

\section{Resumen}

Este escrito se propone presentar una experiencia de prácticas en un servicio público de salud mental, teniendo como foco las vivencias, dificultades e inquietudes surgidas en el curso de la aplicación de una intervención que se produjo en cinco encuentros y que tenía como objetivo trabajar el equipo de un CAPS Infantil del interior del Rio Grande do Sul, mediante el uso de dispositivos que servían como desencadenantes de las discusiones realizadas durante las reuniones de equipo del servicio. Se utilizó autores ligados al movimiento institucionalista, pues la intervención pretendía desnaturalizar y problematizar el cotidiano de trabajo del equipo, disparando movimientos de inquietación y reflexión en los profesionales. Se concluye que la vivencia de los dispositivos propició momentos de creación, de repensar la práctica en el servicio, de problematizar la rutina y el deseo de inventar nuevos modos de hacer salud mental, conduciendo a la flexibilización de las prácticas del equipo local.

Palabras clave: Prácticas en salud mental. CAPS Infantil. Análisis institucional.

\section{Diálogo inicial}

É

aspirar o ar. É respirar devagar. É tragar o vento. É sensibilizar-se com o mundo. Escrita que necessita ser escrita. Que jorra de mim com ímpeto. Furiosa. Travessa. Atrelada ao meu corpo, diz coisas com o que a minha razão jamais se atreveria a usar saliva. Barthes (1973) já dizia que o corpo não fala a mesma língua que a razão. Escreverei fluxos. Fluxos que levarão a prática de uma estagiária de psicologia a delinear-se ao longo deste ensaio, o qual é derivado de uma intervenção realizada com profissionais de um CAPS Infantil de um município do interior do Rio Grande do Sul.

Sem objetivos rígidos, quero cantar. Seguindo o excerto "seria bom se, nos cursos de psicologia, se lesse (sic) menos livros e se ouvisse mais música" (Alves, 2001, 
p. 79), a minha principal expectativa em relação a este escrito é que ele seja uma canção. Que o leitor escute uma música ao se apropriar das ideias lançadas. Por quê? Porque a música sensibiliza, porque os compositores tocam em instrumentos aquilo que, antes, fora tocado pelo corpo (Alves, 2001). A música só acontece ao passar pelo corpo. $\mathrm{O}$ afetar-se só acontece ao passar pelo corpo. A leitura só se torna uma canção ao passar pelo corpo. Assim, a escrita será delineada através de "faixas", as quais fazem alusão às faixas musicais de um $\mathrm{CD}$.

Rolnik (2007) entoa que é função do cartógrafo ${ }^{1}$ dar língua a afetos que pedem passagem, bem como abocanhar as linguagens encontradas que lhe parecerem elementos possíveis à composição cartográfica. Ao articular a ideia da autora à composição musical e ao despertar da sensibilidade, é possível dizer que é tarefa do cartógrafo, além de dar língua a afetos, cantá-los a partir do encontro entre os corpos, do encontro que afeta e potencializa. É imprescindível, também, que além de cantar, as músicas que vão se compondo no território sejam ouvidas. Afetar também tem a ver com ouvir as canções entoadas. Ter sensibilidade em ouvir o invisível. Já dizia Saint-Exupéry (2004, p. 72): "O essencial é invisível aos olhos". Assim, foi ao olhar para o invisível que foi criada a proposta de intervenção que aqui será apresentada.

O Centro de Atenção Psicossocial (CAPS) Infantil compõe a rede de atenção à saúde mental de seu município-sede. É voltado ao atendimento de crianças e adolescentes portadores de transtornos mentais severos e persistentes e, ou, dependentes de álcool ou outras drogas. Contava com uma equipe multidisciplinar composta por duas psicólogas, uma médica e um médico psiquiatras, uma pediatra, duas assistentes sociais, uma terapeuta ocupacional, uma enfermeira, dois técnicos de enfermagem, um educador físico, um professor de música, duas auxiliares administrativas, uma cozinheira e uma servente.

A proposta de intervenção teve como base teórica autores ligados ao Movimento Institucionalista e à Filosofia da Diferença. Objetivou desnaturalizar e problematizar o cotidiano de trabalho da equipe, disparando movimentos de inquietação e reflexão nos profissionais, por meio da interação com os dispositivos lançados e posterior discussão em grupo. Visou a fomentar a criação, repensar a prática, problematizar a rotina e inventar novos modos de se fazer saúde.

A intervenção, ocorrida em cinco encontros e realizada com cerca de dez profissionais, contou com a apresentação e posterior discussão dos seguintes dispositivos criados na experiência de estágio: leitura do texto "A complicada arte de ver”, de Rubem Alves; pintura em mandalas; exposição de duas réplicas do pintor impressionista Monet; performance sombra; folha em branco; massa

Pesquisador que compõe com o campo. Está no meio, entre pulsações, e não apenas coleta e analisa informações (Barros \& Kastrup, 2009). 
de modelar. A realização de tal proposta bem como as sensações e percepções do estágio serão descritas/escorridas no decorrer desse trabalho; escorrer sem fim.

\section{Faixa 1}

Muitas eram as sensações que me invadiam antes da efetivação da proposta de intervenção. A insegurança sentida me levou a experimentar inúmeros caminhos, perceber-me "sem chão" e construir, a partir dessa desestabilização, um caminho à minha maneira. Caminho construído no encontro com o coletivo e com as vivências experimentadas e não rígido ou prévio e que acabasse por estagnar os processos, o que se aproxima das problematizaçóes de Baremblitt (2002): seguir muitas regras na intervenção é que nem nadarmos pensando nas regras que aprendemos quando começamos a nadar: primeiro levantar o braço direito, depois o esquerdo, em seguida, bater as pernas coordenadamente... Ao nadarmos assim, nós nos afogamos, embora seja o jeito mais correto de fazê-lo.

As mudanças no meu processo enquanto estagiária foram perceptíveis, pois este estava em andamento, sendo criado. Provocava-me, invocava-me, atiçava-me e também me deixava estagnada em alguns momentos, para que um pouco de ar chegasse aos pulmões. Parada no sentido de parar, mas também de parada de ônibus, van ou táxi, no sentido de pegar um transporte que me levasse a outros lugares. Os lugares diferentes e a vivência distinta a cada dia atrelavam-se a mudanças que ocorriam externamente, mas também a mudanças internas, reflexo da apropriação de alguns conceitos, mas principalmente da minha apropriação como futura profissional.

\section{Faixa 2}

No decorrer do estágio no CAPSi, as minhas participações em oficinas foram sendo estabelecidas. Oficina de futsal, oficina de artesanato e grupo de familiares passaram a ser lugares mais fixos. Passei a ter definidos os dias em que participaria de cada grupo, e isso me fez experimentar constância em meio ao caos que muitas vezes inundava meus pensamentos. Qual era o meu lugar no serviço? Qual teria que ser o meu lugar no serviço? Eu teria que ter um lugar ou este seria construído ao longo dos dois semestres do estágio?

Aos poucos, percebi que o meu lugar seria resultado de uma construção que iria se dar dia a dia. Eu não tinha como prevê-la por inteiro, nem impedila de se manifestar. A única coisa que deveria estar no serviço, por inteiro, era 
eu. Esses questionamentos em relação ao meu lugar no CAPSi parecem se aproximar das indagaçôes sobre o papel ou lugar dos estagiários de Psicologia em outro CAPS Infantil (Cassel et al., 2010). De acordo com a pesquisa realizada em outro CAPSi, o estágio em serviços desse tipo demanda que o estagiário apresente um preparo que extrapola as teorias estudadas durante a graduação. Além disso, implica que o estudante tenha "uma postura crítica frente as suas intervenções, nas mais diversas possibilidades de atuação que o serviço dispõe" (Cassel et al., 2010, p. 60).

\section{Faixa 3}

Por que decidi que a proposta seria com os profissionais? A intervenção foi planejada no semestre anterior à sua execução, com base nas vivências no CAPSi. A oficina de artesanato, em especial, levou-me a pensar em criação e no quanto as práticas, às vezes, são naturalizadas. A ideia de intervir com os usuários dessa oficina foi despertada. Porém, percebi que a falta de criação que eu sentia em determinado espaço do serviço indicava um ponto de algo mais complexo... Construção social? Busca de comodidade? Londero (2011) frisa sobre a comodidade e a busca do cotidiano levarem a uma impotência para o criar. Procura-se a comodidade e o cotidiano em detrimento da incerteza, da criação, das transformações... Por quê? Todas essas perguntas foram guias e, ao mesmo tempo, "desvirtuadoras" da minha ideia inicial.

Percebi que o que eu observava na oficina de artesanato era apenas um recorte do que acontece em grande parte da saúde pública e, por que não, na sociedade. Cantando com Londero (2011), entoo que o desamparo leva ao sensível. As dúvidas que me deixaram várias vezes com a sensação de desamparo, talvez, se não tivessem sido experimentadas e me levado à desestabilização, não teriam me sensibilizado e me possibilitado criar uma proposta de intervenção a partir desse sensível. Fui do caos à reconstrução Pavlovski (como citado em Londero, 2011). Ou seja, vivi um caos até me assegurar em minha intervenção e nas mudanças que tiveram de ser feitas até a efetivação dela.

O olhar que não estranha mais, pois já se habituou ao que vê, a sensibilidade que é anestesiada pela correria do dia a dia e pela necessidade de atendimentos ininterruptos foram alguns pontos que meu olhar potencializado pela afetação me fez questionar. E me fez olhar de novo. E me fez brincar com os recursos que eu tinha. E me fez construir não a minha proposta de intervenção, mas um projeto a ser mexido e remexido ao ser colocado em ação com o coletivo do CAPSi. 
Assim, provocar os profissionais do CAPSi, com vistas à problematização de suas práticas, bem como à desnaturalização destas, passou a ser a minha ideia de intervenção reformulada. Para que a provocação fosse, de alguma forma, realizada, fiz um cronograma com atividades a serem propostas para a equipe, operando como dispositivos a serem lançados durante algumas semanas na sala de equipe, seguidos de discussóes acerca de como estes operariam, que associações disparariam.

Compreendo o conceito de dispositivo como algo "a serviço da produção, do desejo, da vida, do novo" (Baremblitt, 2002, p. 67). A partir da leitura do autor mencionado, o dispositivo pode ser visto como transformador, provocador de rupturas, disparador de questionamentos, desestabilizaçôes, novos pensamentos e ideias. Além disso, tem as mais variadas materialidades, bem como extrapola os territórios estabelecidos e os atravessa, "[...] conectando singularidades cuja relação era insuspeitável e imprevisível. Gera, assim, o que se denomina linhas de fuga do desejo, da produção e da liberdade, acontecimentos inéditos e invenções nunca antes conhecidas" (Baremblitt, 2002, p. 67).

Importante ressaltar que, ao pensar em intervir na equipe do CAPSi, tentei partir da ideia de não chegar com um saber pronto ou com uma ideia prévia do que o grupo precisaria. Procurei manter uma relação de horizontalidade com o coletivo (Baremblitt, 2002). Ou seja, mantive-me aberta às transformaçôes que viriam quando a proposta de intervenção fosse colocada em prática, bem como às possíveis controvérsias e resistências que poderiam surgir. Controvérsias e resistências dos profissionais, do serviço, minhas e também atreladas a outras intervenções ocorridas, antes, no local, e aos efeitos que produziram na equipe.

\section{Faixa 4}

O primeiro momento em que tive, de modo mais concreto, contato com a proposta formulada foi quando falei na reunião de equipe sobre a intervenção, solicitando autorização para ocupar dez minutos das cinco reunióes seguintes para discussão dos dispositivos que lançaria durante a semana no serviço. Senti que a proposta, de modo geral, teve boa aceitação do grupo. Senti, todavia, a minha resistência, a qual apareceu de modo mais evidente no dia em que, efetivamente, comecei a lançar os dispositivos.

$\mathrm{Na}$ ocasião mencionada, ao chegar ao serviço, vi-me presa a alguns modos de se chegar e fazer a intervenção, bem como de se estagiar. Como romper com a prática pronta e naturalizada, se eu também estava imersa em determinado 
modo de intervir? Londero (2011) fala em burocratização da existência atrelada à disciplina. Como romper com a burocratização e a disciplina que me perpassavam, cair no incerto, na criação de modos de intervir, em vez de cair na reproduçãao de modos de intervir?

Descobri que os dispositivos provocariam os profissionais, mas também a mim. Como eu poderia ter controle do que iria acontecer frente aos dispositivos lançados? $\mathrm{O}$ experimentar intensidades dessubjetiviza, desterritorializa, desmapeia (Rolnik, 2007). O não ter um mapa para chegar a determinado local, a "não certeza" do que emergirá, já demonstra um mergulho nas intensidades? Percebi que eu não tinha como ter controle, e isso me angustiou no primeiro dispositivo lançado: deixar textos do Rubem Alves sobre a mesa dos profissionais. Ao fazê-lo, percebi que estava com receio quanto à aceitação da proposta pela equipe; porém compreendi que, em vez de esperar aceitação, o meu papel, naquele momento, aproximava-se mais de provocação.

Baremblitt (2002) fala em analisadores artificiais e analisadores espontâneos. Estes últimos remetem a fatos que simplesmente acontecem, por isso são chamados, também, de analisadores históricos. Para fins de explicação, "grande, pequeno ou médio, poderia ser uma greve, a morte de um operário, o aumento das doenças de trabalho, uma grande briga" (Baremblitt, 2002, p. 102). Quanto aos analisadores artificiais, o autor mencionado os descreve como sendo construídos, propostos. Assim, refere-se a quando o interventor propõe um dispositivo agitador, ativador... O qual poderá ser aceito ou não pelo coletivo, bem como poderá funcionar ou não.

A partir das explanações sobre analisador artificial e dispositivo, fiquei pensando se os recursos usados como meios para o trabalho realizado no CAPSi poderiam ser chamados de dispositivos ou de analisadores artificiais. Nesse processo, percebi que, apesar de as duas noções aproximarem-se nas suas descrições, mas serem provenientes de caminhos conceituais diversos, os recursos utilizados no serviço em que estagio portavam características que aproximavam as duas noções.

Destarte, o que foi lançado construiu-se pelo contato com a equipe e das vivências que experienciei, intuindo movimento. Pode-se pensar, então, que se articula ao conceito de analisador artificial. Ao mesmo tempo, porém, o que lancei buscava a produção, o desejo, a transformação, a provocação de rupturas, inquietudes, novos pensamentos e ideias, o que se relaciona ao conceito de dispositivo.

Os textos ficaram cinco dias sobre a mesa. Durante esse tempo, alguns analisadores espontâneos (Baremblitt, 2002) fizeram-se presentes. Por um 
dia, por exemplo, os textos foram tirados da mesa por um dos profissionais do CAPS e guardados, por medo de que fossem utilizados como rascunho. Algumas vezes, também vi pastas e prontuários serem colocados sobre o escrito de Rubem Alves.

No dia da reunião de equipe, propus a discussão do dispositivo lançado durante a semana. Procurei manter-me aberta aos apontamentos e impressões dos profissionais, incentivando-os a falar. Uma das falas abordou os vários olhares que uma equipe, por meio de seus diferentes componentes, tem sobre um paciente e a importância disso. Vários olhares no sentido de diferentes profissionais. Tal discurso articula-se à proposição de Baremblitt (2002) sobre a divisão em especialidades existir apenas dentro da equipe e não para os usuários, uma vez que a realidade não ocorre de forma fragmentada e especificada para determinada especialidade apenas. Se o sujeito humano é um ser complexo, como espedaçá-lo? Como não o ver como um todo? Essas questôes articulam-se à fala de outro profissional do CAPSi, o qual destacou que o texto utilizado como dispositivo possibilitou a reflexão sobre a importância de compreender o usuário em seu contexto, levando à ampliação do olhar sobre o Outro.

Depois que os profissionais colocaram suas impressões, expus sobre os motivos de ter levado o texto, destacando a intenção de utilizá-lo para sensibilizar a equipe, deslocar, repensar, instigar a criação. Acrescentei que, com base nas vivências que tivera até o momento no local, percebi que o excesso de demandas a "dar conta" tendia a tornar o trabalho naturalizado e monótono. Horários rígidos a cumprir... Torna-se naturalizado e monótono. E o texto exposto (ao ressaltar o espanto do autor diante de uma simples cebola, transformando-a em uma obra de arte, e levando-o a se espantar com tudo o que via: tomates, pimentôes...) poderia servir para instigar novos movimentos e paradas para reflexão sobre a prática de cada um que compõe a equipe CAPSi.

Como se espantar com o que acontece no serviço? E será que esse espantarse não tornaria a prática ainda mais extenuante, uma vez que haveria um afetar-se envolvido? Como se afetar sem se destruir? Como transformar o que se vê em obra de arte? Como olhar de outro jeito para determinado paciente, para aquele colega, para as situaçóes?

Ao final, falei que a intenção da proposta não se referia a trazer verdades, e sim construí-las com a equipe, para que fossem discutidas e reconstruídas. Assim, canto com Guirado (2010) que o profissional que se utiliza da análise institucional é desalojado do lugar de intérprete dos movimentos grupais e a 
ele não se delega a tarefa de interpretação e sim de ruptura na burocracia das relações instituídas.

Comentei, também, na discussão realizada na reunião, que colocaria uma caixa na sala dos profissionais, para que, no momento em que tivessem contato com os dispositivos, já pudessem escrever ou depositar na caixa suas impressões, para que não as perdessem até a próxima reunião de equipe técnica.

A partir da discussão e das vivências com a equipe do CAPSi, senti que o próximo dispositivo poderia ser uma pintura de mandalas. Assim, no dia seguinte, cheguei ao serviço e fui abordada por um dos profissionais, que me viu com a caixa que seria utilizada para a intervenção e perguntou qual seria o dispositivo. Senti o interesse dele, e isso me motivou. Notei que algum movimento ocorria; seria isso um movimento instituinte?

Em notas esboçadas sobre o instituinte, ele é demarcado como uma "dimensão ou momento do processo de institucionalização em que os sentidos, as ações ainda estão em movimento e constituição" (Guirado, 2010, p. 42). Fiquei pensando em como o interesse pelo dispositivo que seria lançado poderia estar articulado a um interesse por algo da ordem dos afetos, da arte, dos encontros... Daquilo que não estava no cronograma ou na rotina de atendimentos. Seria um movimento em direção à invenção e à ruptura de modos de se trabalhar/cuidar/tratar?

Quando chegou o psiquiatra ao serviço, percebi como eu ainda estava atrelada à ideia de a Medicina apenas receitar e diagnosticar. Pensei: por que ele iria querer pintar? Será que deixaria um pouco de lado seus receituários e carimbos, para pintar uma mandala? Com essas perguntas, percebi o quanto estava envolvida pela hierarquia dos saberes, pelo tecnicismo atrelado à Medicina agarrando-me ao instituído. $\mathrm{Ou}$ seja, à cristalização dos processos, das ações, dos movimentos (Guirado, 2010).

O dispositivo da pintura das mandalas também contou com uma discussão em uma das reuniōes. Pedi que a equipe falasse sobre o pintar, as sensações experimentadas, os movimentos ocasionados no serviço. Um dos profissionais disse que pintar as mandalas representou voltar a ser criança. Lembrei-me, então, das três metamorfoses do espírito de que fala Nietzsche (1979): o camelo se torna leão, que se torna criança. $\mathrm{O}$ camelo refere-se ao espírito que não questiona, pois tem uma vida servil. Já o leão grita, mete medo nos outros, é corajoso. O espírito criança, porém, inventa o tempo inteiro. Cria. Diz sim à vida. Não está preocupado com o que pensam dele. É pura experimentação. Se o pintar mandalas representou voltar a ser criança, o dispositivo lançado fez algo se mexer. Espernear? Gritar? Um voltar a estranhar o mundo, a olhar para as coisas como se fosse pela primeira vez, a perguntar mil vezes: por quê? 
$\mathrm{Na}$ caixa que foi deixada na sala dos profissionais, havia duas frases: uma delas atribuía-se a Nietzsche e dizia o seguinte: "Quando se olha muito para o abismo, o abismo olha de volta”. Durante a discussão, o profissional que a depositou remeteuse à importância de quem trabalha em um CAPSi se cuidar, se tratar, pois o lidar com a loucura pode levar a adentrar na loucura do outro. Chamou a atenção que, ao final da reunião, surgiu a questão da importância de serem oferecidos atendimentos psicológicos aos profissionais que trabalham com saúde mental. Será que a minha intervenção e a discussão sobre a importância de os profissionais se cuidarem despertou a questão? Será que a discussão travada a partir do dispositivo que lancei provocou um movimento de autoanálise ${ }^{2}$ no grupo?

Seguindo o cronograma de intervenção, na semana seguinte, procedi à realização do dispositivo "quadros", o qual consistiu na exposição de duas réplicas de quadros (da série das Nenúfares) do pintor impressionista Monet, nas quais ele retrata o jardim de sua casa (Ronquillo, 2012). As obras ficaram expostas na sala de equipe, na parede acima da caixa (comentada anteriormente), e revistas foram deixadas ao lado, junto à frase "Ao permitir-se impressionar pelos quadros... escolha uma ou mais figuras nas revistas... coloque o que recortar na caixa ao lado".

Passaram-se alguns dias. A reunião de equipe técnica foi realizada e, com ela, a discussão em relação ao dispositivo dos quadros. Diferentemente das discussões anteriores, minhas sensações, bem como as incertezas dos profissionais acerca dos quadros, indicavam que, dessa vez, seria mais válido eu iniciar falando o que estes representavam na minha proposta de intervenção, para situar a discussão. Expliquei, então, que essas obras inseriam-se no movimento artístico chamado Impressionismo, o qual propunha a desconstrução do que era produzido até determinado período. Acrescentei que, impulsionados por esse movimento, os artistas começaram a sair de seus ateliês para ocuparem as ruas, visando a sentir e se impressionar com o que viam, para então produzirem obras baseadas em suas impressões, escapando aos modelos predeterminados de fazer arte (Kelder, 1997). Ressaltei que o dispositivo dos quadros visava a relacionar a ideia de desconstrução à capacidade de deixar-se impressionar pelo que afeta, de forma articulada à busca da desconstrução das práticas naturalizadas e do despertar de um olhar mais sensível.

Interroguei à equipe: seria possível uma prática baseada na sensibilidade, no se afetar e se impressionar? Até que ponto uma prática assim (embora implique criação e questionamento) pode adoecer o profissional que a executa?

\footnotetext{
Autoanálise consiste em que os coletivos, como protagonistas de seus "problemas, necessidades, interesses, desejos e demandas, possam enunciar, compreender, adquirir ou readquirir um pensamento e um vocabulário próprio" (Baremblitt, 2002, p. 17). Ou seja, não consiste em alguém de fora ou de cima trazer respostas ou dizer o que o coletivo pode ou deve fazer.
} 
Os comentários variaram. Varri para dentro de mim a complementaridade imprescindível entre técnica e afetação, a partir da discussão que se travou. Um dos profissionais revelou que, logo que começou a trabalhar no CAPSi, afectava-se - afectar-se pensado com base em Deleuze (2006): sofrer a ação de outro corpo. Nesse caso, o profissional sofrer a ação do que acontecia no CAPSi; e se impressionava mais com as coisas do que hoje. Essa colocação me levou à harpa, a sons que me fizeram sentir a proposta de intervenção como uma possibilidade de levar os profissionais a potencializarem-se. Como? Pelo encontro ao acaso entre corpos. Acaso que, ao acaso, poderá fazer com que certos corpos convêm com o nosso, forneçam alegria e aumentem a nossa potência (Deleuze, 2006).

Seria possível cantar os quadros, ou outro dispositivo utilizado, como uma melodia que, ao encontrar o corpo de cada um que compóe a equipe CAPSi, movimentaria em direção ao aumento da potência? Aumento da potência, nesse caso, entoado pelo estranhar o que acontece no serviço, ou seja, não olhar as situações como comuns. É possível sentir que a intensificação da potência quer o acaso Nietzsche (como citado em Dias, 2004). É possível sentir, além disso, que é o acaso o "elemento essencial que determina a plasticidade da vontade criadora" (p. 143).

Vontade criadora. A discussão foi levada pelos batuques... Um deles, estrondoso, fez ressoar: a teoria nos ajuda a lidar com as situações, todavia, nos momentos em que ela não nos serve, só a criatividade nos acode. Percebi que toda a invenção de Monet exposta na sala dos profissionais tinha movimentado algo da ordem (ou seria da desordem?) da criação. Utilizo arranjos para embalar a questão da criação. Embalar. Arremessar a criação para um terreno musical que entende o criar não como um ato particular Nietzsche (como citado em Dias, 2004). Criar arremessado, então, para além do expor quadros? Para além da clave de sol, pois criar seria inventar um sol próprio? Nietzsche (como citado em Dias, 2004)

Outro profissional afirmou que muita teoria ou o fato de nos focarmos apenas nesse aspecto, às vezes, impede-nos de perceber o sofrimento do outro. Tal questão me fez lembrar a distinção entre o ato de ver e o de olhar, cantada por Cardoso (1988). De acordo com esse autor, o olhar permite a construção de novos sentidos, exige o rompimento de paradigmas, deixa que se vá para além do que já se sabia. É o oposto do ato de ver, pois este último vê o mundo acabado e total, coerente e contínuo. Deter-se apenas à teoria atrapalha o olhar para o usuário? Como saber o limite entre o uso da teoria e o uso do olhar sensível? 
Envolvida pelas práticas naturalizadas que abocanham os profissionais do CAPSi, senti que era o momento de efetivar o dispositivo da performance sombra, o qual consistia em imitar a equipe em seus afazeres cotidianos, para disparar movimentos de reflexão sobre a rotina, a possibilidade de se pensar em outros modos de se fazer saúde, o despertar de novos questionamentos.

A performance foi o dispositivo que mais me permitiu abrir o corpo às experimentações do espaço do CAPSi. Abrir que, de início, estava emperrado. No primeiro dia em que deveria realizar o dispositivo, o constrangimento me sugou. Não consegui me sentir confortável desempenhando tal papel. Apareceu, nesse momento, o quanto eu era um dos componentes da intervenção, necessitando também romper amarras e ideias preconcebidas sobre como se pratica Psicologia. O quanto estávamos descobrindo juntos (eu e equipe) os sabores da invenção e de outros modos de se fazer seja lá o que for!

Voltando o CD, passados alguns dias, voltei ao serviço sentindo-me mais encorajada a encarar o movimento do meu corpo e o movimento dos outros corpos. Composições. Imitei vários profissionais, e eles pareceram incomodados, mas, ao mesmo tempo, levaram de modo leve, na brincadeira. A imitação de alguns profissionais me fez pensar em como é difícil ser outra pessoa quando estamos tão acostumados aos nossos modos de ser. Como se fazer de sombra dos profissionais sem olhar para as minhas sensações, sem olhar para o envolto social que cobre cada um, sem olhar para as inúmeras instituições que perpassam a equipe?

O meu envolvimento com a intervenção me levava a caminhos que não bifurcavam apenas na discussão do "ser sombra" dos profissionais que tive a oportunidade de imitar. A sensação que me atropelava pedia mais. Pedia que todos os profissionais passassem pela experiência de serem imitados. E como realizar isso? Resplandeceu a dinâmica do espelho ${ }^{3}$ no espaço destinado à intervenção durante a reunião, com o objetivo de promover a desinibição dos profissionais para a discussão que se seguiria, bem como possibilitar que todos passassem pela experiência de serem imitados. Os profissionais realmente se movimentaram fisicamente, e percebi que se entusiasmaram com a proposta, mostrando-se envolvidos e divertindo-se com a situação.

A equipe declarou que o ser imitado de modo "natural", ou seja, quando a pessoa está fazendo algo da sua rotina, provoca mais; já o imitar de modo mais artificial, como acontece na dinâmica do espelho, não desassossega tanto.

Dinâmica que consiste em dividir o grupo em duplas, de modo que um fique de frente para o outro. Inicialmente, um do par imita o outro, como se fosse um espelho, depois invertem os papéis na dupla. 
A discussão, do meu ponto de vista, não rendeu tantos questionamentos e apontamentos quanto os dispositivos anteriores. Será porque o dispositivo não funcionou? E o que seria funcionar?

A folha em branco (último dispositivo) foi deixada na mesa da sala de equipe com canetinhas, lápis de cor, revistas, cola, tesoura, com o seguinte dizer: "O que a intervenção vem movimentando? Crie!”.

Alguns dias após o lançar do dispositivo, avistei, ao chegar ao serviço, uma pintura se fazendo na entrada. Uma pintura que representa o logotipo do CAPSi. Logo pensei ser ousadia demasiada pensar que tal pintura fosse o reflexo dos dispositivos lançados, mas foi impossível deixar de pensar que a criação era o que buscava suscitar na intervenção.

$\mathrm{Na}$ última discussão, falei sobre como eu havia percebido a proposta. Dei palavra, basicamente, a sensações que descrevi até o momento neste ensaio. Propus uma conversa sobre o último dispositivo e sobre como sentiram a intervenção. Levei massa de modelar e pedi que representassem, por meio dela, o que a proposta de intervenção significou, sensibilizou, deixou de pulsação. A discussão principiou pelo que surgiu a partir da folha em branco que deixei no CAPSi. Solicitei que quem havia escrito comentasse sua produção. Três frases foram escritas: "Toda intervenção gera um infinito de possibilidades"; "É uma autoanálise! Um questionamento!"; "Todas as atividades propostas geraram momentos de reflexão". Nada de colorido, de recorte. Será? Que cor, que arte, que sons tinham as frases?

A discussão foi intensa. A intervenção foi comentada como momento de parada e de reflexão em meio a uma prática árdua. Expuseram sobre o quanto seria interessante seguir com esses momentos de parada durante as reuniôes. Não necessariamente com dispositivos, mas parar para pensar a própria equipe. Colocaram que, muitas vezes, a reunião não rendia, tornavase cansativa, porque não havia um espaço como esse. Referiram que não seria uma perda de tempo e sim um novo impulso para as discussóes de caso. Reflito se é necessário um momento formal de parada ou se o simples repensar de cada um já contribuiria para pequenas mudanças. Talvez o movimento não precise ser algo que se veja ou que tenha um tempo para ocorrer. Talvez seja mais da ordem do acontecimento, do sentir diferenciado.

Depois da discussão, distribuí a massa de modelar e pedi que os profissionais representassem por ela o que a intervenção significou, movimentou. Pela primeira vez, todos falaram e mostraram o que haviam produzido. Soltura, desestabilização, questionamentos, produção de um olhar mais sensível, espaço para se dar língua a afetos (Rolnik, 2007) foram, em suma, as percepções que 
apareceram por meio das representações "modeladas". Representações que, importante frisar, estão sujeitas a remodelações. Modelar sem fim.

\section{Faixa 5}

A modelagem continua, promovendo articulações diversas. Por exemplo, uma intervenção realizada em outro CAPSi baseou-se na criação de um espaço de convivência. Embora tal espaço fosse destinado aos usuários do serviço, possibilitou que os profissionais fossem apoiados e instigados "a desenvolver atividades nesse espaço terapêutico ampliado" (Moraes, Dias, Romio \& Peixoto, 2011, p. 1057), o que levou à flexibilização das práticas do serviço (Moraes et al., 2011).

Pode-se pensar, destarte, uma articulação entre a flexibilização mencionada acima, resultante de outra intervenção, e o repensar as práticas do serviço no qual foi realizada a intervenção deste escrito. Isso porque, como repensar as práticas sem que a flexibilização se evidencie? Sem que a rigidez movimentese, modele-se? Será possível, a propósito, pensar a flexibilização das práticas, no CAPS da pesquisa que se delineia neste artigo, como um dos aspectos potentes resultantes da intervenção realizada com o coletivo?

\section{Faixa 6}

Mas é preciso que exista um fim. Seja um fim provisório, um fim que dança ou que vibra, um fim que seja o fim apenas neste momento, mas um fim. Os dispositivos construídos com a equipe do CAPSi não finalizaram. As pulsações estão presentes, seja no campo visual ou no palco do invisível. A intervenção de estágio cantada neste ensaio é apenas um recorte do que se pode fazer ao se libertar de algumas amarras cientificistas ou predeterminadas. Que o fim seja o começo de outra canção.

Permanece a sensação de incerteza. Incerteza que potencializa certezas outras. Certezas várias. Permanece a sensação de canção entoada e que deixou tons a serem cantados em outras melodias. Permanece a sensação de movimento. De respingos produzidos no encontro. Respingos que escorrem. Vão se espalhando, unindo-se, inundando tudo. Respingos que não são mais apenas respingos. Inventam. São crianças.

A flexibilização das práticas de serviço do CAPSi pode ser pensada como um dos aspectos resultantes da intervenção realizada, como referido anteriormente. Não obstante, é possível ampliar o olhar para a estagiária que efetivou a intervenção no serviço e atentar para as impressões e inquietudes 
que foram expressas ao longo da escrita e que dizem não apenas da própria estagiária, mas de um local de estágio que extrapola as teorias estudadas na graduação (Cassel et al., 2010). Diante disso,

Como promover uma produção de conhecimentos que não sirva a fins exclusivamente pragmáticos, e sim enriqueça o mundo humano? Como praticar uma atividade intelectual que exercite e desafie o pensamento, sem limitar-se à sua aplicação meramente instrumental? (Lobosque, 2010, p. 18)

Como?

\section{Referências}

Alves, R. (2001). Se eu fosse você... In R. Alves. O amor que acende a lua. (pp. 73-79). Campinas: Papirus.

Baremblitt, G. (2002). Compêndio de análise institucional e outras correntes: teoria e prática (5a ed.). Belo Horizonte: Instituto Félix Guattari.

Barros, L., \& Kastrup, V. (2009). Cartografar é acompanhar processos. In E. Passos, V. Kastrup, \& L. Escóssia (Org.). Pistas do método da cartografia: pesquisa-intervenção e produção de subjetividade. (pp. 52-75). Porto Alegre: Sulina.

Barthes, R. (1973). O prazer do texto. São Paulo: Perspectiva.

Cardoso, S. (1988). O olhar viajante (do etnólogo). In A. Novaes (Org). O olhar. (pp. 347-360). São Paulo: Companhia das Letras.

Cassel, P. A., Tomm, E., Culau, F. S., Wottrich, L. A. F., Peixoto, M. J. R., Lena, M. S., \& Dias, H. Z. J. (2010). A clínica da loucura: o papel dos estagiários de Psicologia em um CAPS Infantil. Jornada Psicologia e Saúde: perspectivas atuais de intervençôes em saúde, 2 (pp. 60-63). Santa Maria: Universidade Federal de Santa Maria - UFSM. Recuperado em 9 outubro, 2012, de http://w3.ufsm.br/ppgp/anais_joranda_psicologia.pdf.

Deleuze, G. (2006). Spinoza e as três éticas. In G. Deleuze, Crítica e clínica. (pp. 156-170). São Paulo: Editora 34. 
Dias, R. (2004). A vida como vontade criadora: por uma visão trágica da existência. In Fonseca, T., \& Engelman, S. Corpo, arte e clínica. (pp. 131146). Porto Alegre: Editora da UFRGS.

Guirado, M. (2010). A análise institucional do discurso como analitica da subjetividade. São Paulo: Annablume.

Kelder, D. (1997). O melhor do impressionismo francês. São Paulo: Ática.

Lobosque, A. (2010). Produção de saberes e políticas de verdade. In A. M.Lobosque, (Org.). Seminário saúde mental: os desafios da formação. (Caderno Saúde Mental, vol. 3, pp. 17-18). Belo Horizonte: ESP-MG.

Londero, M. (2011). O acontecer na clinica: quando o criar resiste ao cotidiano. Dissertação de Mestrado, Universidade Federal do Rio Grande do Sul, Porto Alegre, RS, Brasil.

Moraes, N., Dias, H., Romio, C., \& Peixoto, M. (2011). Intervenção em saúde mental: construindo um ambiente terapêutico em um CAPS InfantoJuvenil. Revista Contexto \& Saúde, 10 (20), 1055-1060.

Nietzsche, F. (1979). Assim falava Zaratustra. São Paulo: Hemus.

Rolnik, S. (2007). Cartografia Sentimental: transformações contemporâneas do desejo. Porto Alegre: Sulina.

Ronquillo, U. (2012). O jardim de Monet em Giverny. In The urban earth. Recuperado em 9 outubro, 2012, de http://theurbanearth.wordpress. com/2009/06/02/o-jardim-de-monet-em-giverny/.

Saint-Exupéry, A. (2004). O pequeno Principe (48a ed.). Rio de Janeiro: Agir.

\section{Anexo}

\section{A complicada arte de ver (Rubem Alves)}

Ela entrou, deitou-se no divã e disse: "Acho que estou ficando louca". Eu fiquei em silêncio aguardando que ela me revelasse os sinais da sua loucura. "Um dos meus prazeres é cozinhar. Vou para a cozinha, corto as cebolas, os tomates, os pimentões - é uma alegria! Entretanto, faz uns dias, eu fui para a cozinha para fazer aquilo que já fizera centenas de vezes: cortar cebolas. Ato banal sem surpresas. Mas, cortada a cebola, eu olhei para ela e tive um 
susto. Percebi que nunca havia visto uma cebola. Aqueles anéis perfeitamente ajustados, a luz se refletindo neles: tive a impressão de estar vendo a rosácea de um vitral de catedral gótica. De repente, a cebola, de objeto a ser comido, se transformou em obra de arte para ser vista! E o pior é que o mesmo aconteceu quando cortei os tomates, os pimentóes... Agora, tudo o que vejo me causa espanto." Ela se calou, esperando o meu diagnóstico. Eu me levantei, fui à estante de livros e de lá retirei as "Odes Elementales", de Pablo Neruda. Procurei a "Ode à Cebola" e lhe disse: "Essa perturbação ocular que a acometeu é comum entre os poetas. Veja o que Neruda disse de uma cebola igual àquela que lhe causou assombro: 'Rosa de água com escamas de cristal'. Não, você não está louca. Você ganhou olhos de poeta... Os poetas ensinam a ver”. Ver é muito complicado. Isso é estranho porque os olhos, de todos os órgãos dos sentidos, são os de mais fácil compreensão científica. A sua física é idêntica à física óptica de uma máquina fotográfica: o objeto do lado de fora aparece refletido do lado de dentro. Mas existe algo na visão que não pertence à física. William Blake sabia disso e afirmou: "A árvore que o sábio vê não é a mesma árvore que o tolo vê". Sei disso por experiência própria. Quando vejo os ipês floridos, sinto-me como Moisés diante da sarça ardente: ali está uma epifania do sagrado. Mas uma mulher que vivia perto da minha casa decretou a morte de um ipê que florescia à frente de sua casa porque ele sujava o chão, dava muito trabalho para a sua vassoura. Seus olhos não viam a beleza. Só viam o lixo. Adélia Prado disse: "Deus de vez em quando me tira a poesia. Olho para uma pedra e vejo uma pedra”. Drummond viu uma pedra e não viu uma pedra. A pedra que ele viu virou poema. Há muitas pessoas de visão perfeita que nada veem. "Não é bastante não ser cego para ver as árvores e as flores. Não basta abrir a janela para ver os campos e os rios", escreveu Alberto Caeiro, heterônimo de Fernando Pessoa. O ato de ver não é coisa natural. Precisa ser aprendido. Nietzsche sabia disso e afirmou que a primeira tarefa da educação é ensinar a ver. $\mathrm{O}$ zen-budismo concorda, e toda a sua espiritualidade é uma busca da experiência chamada "satori", a abertura do "terceiro olho". Não sei se Cummings se inspirava no zen-budismo, mas o fato é que escreveu: "Agora os ouvidos dos meus ouvidos acordaram e agora os olhos dos meus olhos se abriram”. Há um poema no Novo Testamento que relata a caminhada de dois discípulos na companhia de Jesus ressuscitado. Mas eles não o reconheciam. Reconheceram-no subitamente: ao partir do pão, "seus olhos se abriram". Vinicius de Moraes adota o mesmo mote em "Operário em Construção": "De forma que, certo dia, à mesa ao cortar o pão, o operário foi tomado de uma súbita emoção, ao constatar assombrado que tudo naquela mesa - garrafa, prato, facão - era ele quem fazia. Ele, um humilde operário, um operário em construção". A diferença se encontra no lugar onde os olhos são guardados. 
Se os olhos estão na caixa de ferramentas, eles são apenas ferramentas que usamos por sua função prática. Com eles vemos objetos, sinais luminosos, nomes de ruas - e ajustamos a nossa ação. $\mathrm{O}$ ver se subordina ao fazer. Isso é necessário. Mas é muito pobre. Os olhos não gozam... Mas, quando os olhos estão na caixa dos brinquedos, eles se transformam em órgãos de prazer: brincam com o que veem, olham pelo prazer de olhar, querem fazer amor com o mundo. Os olhos que moram na caixa de ferramentas são os olhos dos adultos. Os olhos que moram na caixa dos brinquedos, das crianças. Para ter olhos brincalhões, é preciso ter as crianças por nossas mestras. Alberto Caeiro disse haver aprendido a arte de ver com um menininho, Jesus Cristo fugido do céu, tornado outra vez criança, eternamente: "A mim, ensinou-me tudo. Ensinou-me a olhar para as coisas. Aponta-me todas as coisas que há nas flores. Mostra-me como as pedras são engraçadas quando a gente as tem na mão e olha devagar para elas". Por isso - porque eu acho que a primeira função da educação é ensinar a ver - eu gostaria de sugerir que se criasse um novo tipo de professor, um professor que nada teria a ensinar, mas que se dedicaria a apontar os assombros que crescem nos desvãos da banalidade cotidiana. Como o Jesus menino do poema de Caeiro. Sua missão seria partejar "olhos vagabundos". 